\title{
Dynamics of hyperphenylalaninemia and intellectual outcome in teenagers with phenylketonuria
}

\author{
Bożena Didycz and Mirosław Bik-Multanowski ${ }^{\varpi}$ \\ Department of Medical Genetics, Faculty of Medicine, Jagiellonian University Medical College, Kraków, Poland
}

\begin{abstract}
Insufficient treatment adherence after early childhood is frequently observed in patients with phenylketonuria. Assessment of these individuals' long-term metabolic control could enable early detection of the risk of intellectual deterioration resulting from high blood phenylalanine concentration. However, the predictive value of specific parameters related to individual dynamics of hyperphenylalaninemia is not clear. Here, we assessed the impact of blood phenylalanine fluctuations during the first 12 years of life on cognitive outcome in early and continuously treated teenagers with phenylketonuria. We have analyzed a total of 5141 results of blood phenylalanine measurements in 32 patients. The phenylalanine levels of these patients were usually acceptable during their early childhood, but the control of hyperphenylalaninemia worsened and the average treatment adherence dropped to $40 \%$ during the late primary school. Our analysis revealed a strong association between the Wechsler intelligence verbal scores and the mean of the yearly means of phenylalanine concentrations $(r=-0.62)$. The correlations of IQ scores with median phenylalanine concentrations and the variability of blood phenylalanine levels gave weaker associations. The Wechsler verbal scores were also strongly correlated with the treatment adherence level during preschool and late primary school ( $r=0.61$ and 0.72 ). The mean of the yearly means of blood phenylalanine concentrations appears to be a better predictor of cognitive outcome in children with phenylketonuria than other parameters related to phenylalanine fluctuations. The percentage of acceptable phenylalanine levels below $50-60 \%$ should be regarded as a "red flag" due to the risk of intellectual deterioration in patients.
\end{abstract}

Key words: inborn error of metabolism; metabolic control of PKU; treatment adherence

Received: 08 February, 2017; revised: 25 April, 2017; accepted: 15 May, 2017; available on-line: 31 August, 2017

e-mail: miroslaw.bik-multanowski@uj.edu.pl Abbreviations: PKU, phenylketonuria; Phe, phenylalanine; S.D., standard deviation

\section{INTRODUCTION}

Phenylketonuria (PKU; OMIM 261600) is the most common inborn error of amino acid metabolism. A lack of sufficient treatment leads to progressive, irreversible brain damage (Burgard et al., 1997; Blau et al., 2010). Depending on the duration and extent of hyperphenylalaninemia, the signs and symptoms of insufficiently treated PKU can range from severe intellectual disability to subtle neuropsychological abnormalities with decreased qual- ity of life (Waisbren et al., 2007; Bik-Multanowski et al., 2008).

Phenylketonuria treatment consisting of a life-long low-phenylalanine diet should be implemented before the end of the third week of life. According to current European treatment policies (van Spronsen et al., 2017), blood phenylalanine (Phe) concentration should be maintained within a range of $2-6 \mathrm{mg} / \mathrm{dL}(0.12-0.36 \mathrm{mmol} / \mathrm{L}$; $1 \mathrm{mg} / \mathrm{dL}=0.06 \mathrm{mmol} / \mathrm{L}$ ) during the first 12 years of life and should not exceed $10 \mathrm{mg} / \mathrm{dL}$ in older patients.

It is generally accepted that a strict dietary regimen promotes normal intellectual development in PKU patients. Unfortunately, due to the pronounced burden of maintaining a low-phenylalanine diet, insufficient treatment adherence is frequently observed among patients (Walter et al., 2002), and Phe concentrations often exceed the recommended range. Moreover, because the signs of phenylalanine toxicity develop slowly, intellectual deficits can remain subtle for a long time. Therefore, the risk of development of intellectual disability in young patients with PKU is considerable.

Follow-up procedures of PKU patients mainly include frequent blood Phe measurements and subsequent adjustment of dietary prescriptions to maintain the blood Phe concentration within the targeted ranges. The quality of long-term metabolic control can be used to predict the risk of intellectual deterioration in a given patient. However, it is not clear which of the parameters related to Phe concentration (e.g., the mean, the median or the changeability of Phe levels) should be watched to predict the cognitive deficits in PKU children (Viau et al., 2001; Anastasoaie et al., 2008; Blau et al., 2010).

In order to define the best Phe-related predictors of suboptimal intellectual outcome, we have analyzed the life-long Phe fluctuations in teenagers with PKU who were followed up in our clinic.

\section{MATERIALS AND METHODS}

A total of 32 teenagers (17 girls and 15 boys), aged 12-15, with classic or mild PKU were included in the study. All of the patients had been followed up in our outpatient metabolic clinic since infancy. Dietary treatment was introduced prior to the end of the third week of life. Table 1 lists the details of the study participants, including their treatment introduction time and the disease-causing mutations of the phenylalanine hydroxylase gene $(P A H)$.

All of the results of blood Phe measurements, available since the neonatal period until the end of the 12th year of life, were assessed for the study participants. The Wechsler Intelligence Scale for Children (WISC-R) was 
Table 1. The studied population.

\begin{tabular}{|c|c|c|c|c|}
\hline $\begin{array}{l}\text { Patient's } \\
\text { number }\end{array}$ & $\begin{array}{l}\text { Age at psycholo- } \\
\text { gical assessment }\end{array}$ & Gender & $\begin{array}{l}\text { Mutations } \\
\text { of the } P A H \text { gene }\end{array}$ & $\begin{array}{l}\text { Treatment start } \\
\text { (week of life) }\end{array}$ \\
\hline 1 & 13 & $\mathrm{M}$ & p.R408W/p.R408W & 2 \\
\hline II & 15 & $\mathrm{~F}$ & p.R408W/IVS12+1g>a & 3 \\
\hline III & 12 & $\mathrm{~F}$ & p.R408W/p.R243Q & 3 \\
\hline IV & 12 & $\mathrm{~F}$ & p.R408W/p.L348V & 3 \\
\hline V & 12 & M & p.R408W/p.R158Q & 2 \\
\hline VI & 15 & $M$ & p.R408W/p.R408W & 3 \\
\hline VII & 12 & $\mathrm{~F}$ & p.R408W/p.R408W & 2 \\
\hline VIII & 14 & $\mathrm{~F}$ & p.R408W/p.R408W & 2 \\
\hline IX & 12 & $\mathrm{~F}$ & p.R408W/p.E183Q & 2 \\
\hline$X$ & 14 & $\mathrm{~F}$ & p.R408W/p.R408W & 2 \\
\hline $\mathrm{XI}$ & 15 & $M$ & p.R408W/p.R408W & 3 \\
\hline XII & 12 & $\mathrm{M}$ & p.R408W/p.R408W & 2 \\
\hline XIII & 12 & $M$ & p.R408W/p.R408W & 3 \\
\hline XIV & 13 & $\mathrm{M}$ & p.R252W/IVS10-11g>a & 3 \\
\hline$X V$ & 15 & $\mathrm{M}$ & p.R408W/p.R408W & 3 \\
\hline XVI & 14 & $\mathrm{M}$ & p.R408W/p.R408W & 3 \\
\hline XVII & 15 & $\mathrm{M}$ & p.R408W/IVS2+5g $>c$ & 2 \\
\hline XVIII & 14 & $\mathrm{~F}$ & p.R408W/p.R408W & 2 \\
\hline XIX & 15 & $\mathrm{~F}$ & p.R408W/p.R408W & 3 \\
\hline$x X$ & 14 & $M$ & p.R408W/IVS9-2a>c & 3 \\
\hline XXI & 12 & $\mathrm{~F}$ & p.R408W/p.R408W & 2 \\
\hline XXII & 15 & $M$ & p.R408W/p.R408W & 3 \\
\hline XXIII & 14 & $M$ & p.R408W/p.R243Q & 3 \\
\hline XXIV & 15 & $\mathrm{~F}$ & p.R408W/N & 3 \\
\hline XXV & 13 & $\mathrm{~F}$ & p.R408W/p.R408W & 2 \\
\hline XXVI & 12 & $M$ & p.R408W/IVS12+1g>a & 3 \\
\hline XXVII & 12 & $\mathrm{~F}$ & p.R408W/p.R408W & 2 \\
\hline XXVIII & 13 & $\mathrm{~F}$ & p.R408W/p.R408W & 2 \\
\hline XXIX & 14 & $\mathrm{~F}$ & p.R408W/p.R408W & 3 \\
\hline$X X X$ & 14 & $\mathrm{~F}$ & $\mathrm{p} . \mathrm{R} 408 \mathrm{~W} / \mathrm{N}$ & 3 \\
\hline$X X X I$ & 14 & $\mathrm{M}$ & p.R408W/p.R408W & 3 \\
\hline XXXII & 13 & $\mathrm{~F}$ & p.R408W/p.R408W & 2 \\
\hline
\end{tabular}

$\mathrm{N}$, not identified

used to assess the intellectual status of every patient between the 13th and 15th year of life.

In order to identify the strongest predicting risk factors of intellectual disability, we have analyzed the correlation of the Wechsler tests (full score, verbal score and performance score) with long-term dynamics of hyperphenylalaninemia. The Phe-related parameters included: the total number of blood Phe measurements, the mean of the 12 yearly mean concentrations during the first 12 years of life, the median blood Phe concentrations within the same period and standard deviation (S.D.) of blood Phe concentrations, representing the variability of Phe concentrations, assessed separately for two periods: $0-6$ years and $6-12$ years.
Additionally, we analyzed the percentage of Phe measurements remaining within the recommended range (an indicator of treatment adherence of the patients) for every patient. These analyses were conducted only for older children and young adolescents, separately for three developmental intervals: preschool (5th-6th years of life), early primary school (7th-9th years of life) and the late primary school (10th-12th years of life). We selected these periods based on the observed tendency of treatment adherence to decrease after early childhood (Walter et al., 2002).

Two-sided Pearson correlation statistics were used. We applied the Bonferroni correction for multiple comparisons to assess the statistical significance of the correlation coefficient $r$.

\section{RESULTS}

A total of 5141 results of blood Phe measurements were analyzed. On average, 161 dry blood-spot tests were performed for each patient. The mean Phe concentration during the first year of life (including the period of diet introduction and stabilization) exceeded $8 \mathrm{mg} \mathrm{dL}$ and subsequently decreased below $7 \mathrm{mg} / \mathrm{dL}$ to stabilize for the next few years near $6.5 \mathrm{mg} / \mathrm{dL}$. It then rose to approximately $8 \mathrm{mg} / \mathrm{dL}$ during the 10th-12th years of life. The S.D. of blood Phe concentrations within the first six years of life were relatively high and reached 6.65 $\mathrm{mg} / \mathrm{dL}$. However, it should be noted that the above period included the initial period of diet introduction and stabilization. In the following years (7th-12th years), the mean S.D. decreased to 3.73 $\mathrm{mg} / \mathrm{dL}$.

The indicator of treatment adherence (the percentage of acceptable Phe results) slightly exceeded $50 \%$ during preschool and early primary school (5th-9th years of life). This indicator then dropped to $40 \%$ during the late primary school period.

The results of the WISC-R test varied between 91 and 141 points with a median IQ within the normal/aboveaverage range (i.e., 114.5 points).

Data analysis of Phe fluctuations revealed a statistically significant association between Wechsler verbal scores and Phe values. In particular, a moderate correlation with the mean of the yearly Phe means was observed in the first 12 years of life $(r=-0.62)$. The correlations of the median Phe concentrations in the same period, as well as of the S.D. of the Phe concentrations in older 


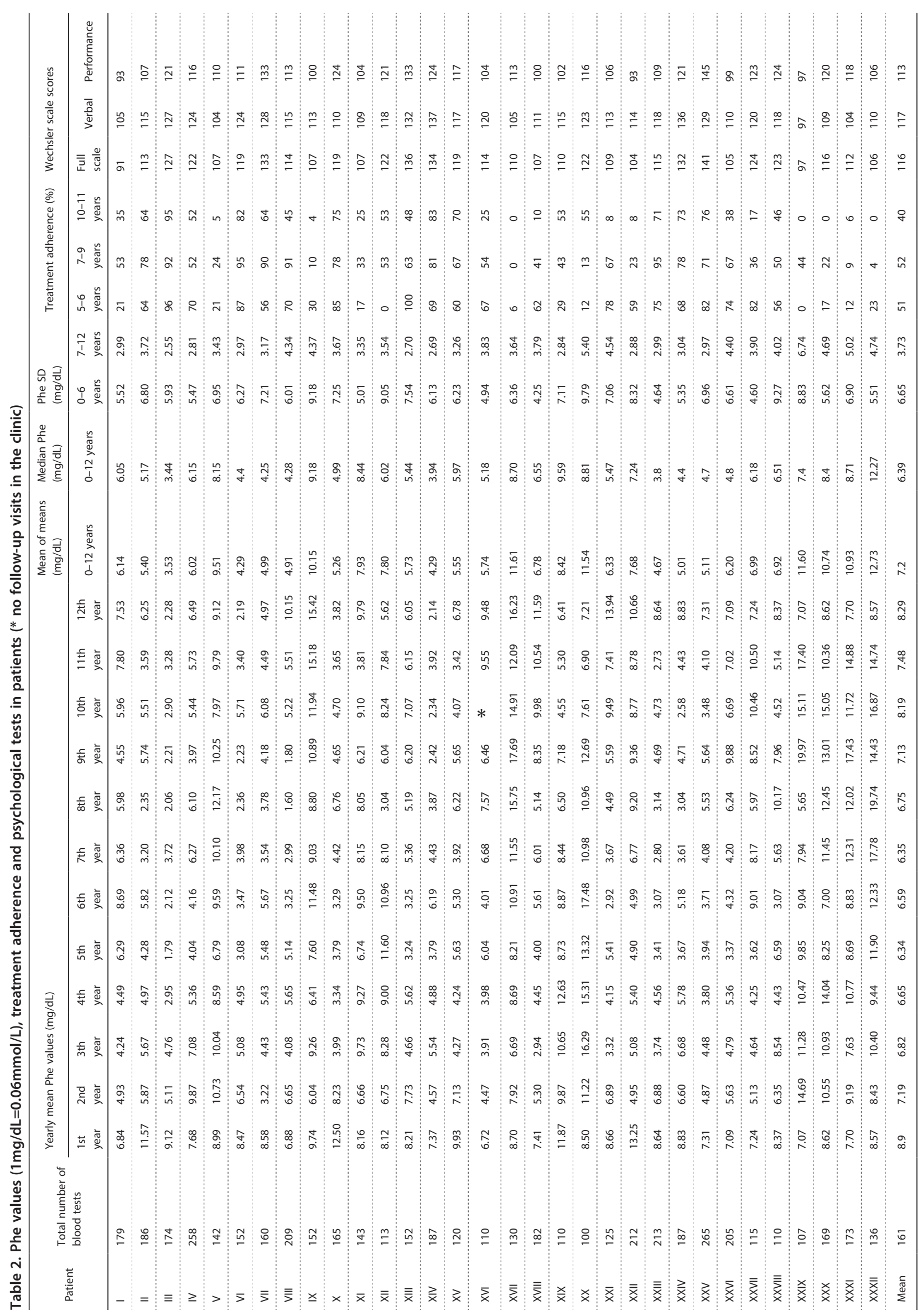


Table 3. Pearson's correlation statistics. Bonferroni correction for multiple comparisons was applied. Corrected $p$-value is provided for statistically significant results $(-0.51>r>0.51)$.

\begin{tabular}{|c|c|c|c|c|c|c|c|c|c|}
\hline & & \multirow{2}{*}{$\begin{array}{l}\text { Total number } \\
\text { of blood tests }\end{array}$} & \multirow{2}{*}{$\begin{array}{c}\begin{array}{c}\text { Mean of } \\
\text { yearly } \\
\text { means }\end{array} \\
\begin{array}{c}0-12 \\
\text { years }\end{array}\end{array}$} & \multirow{2}{*}{$\begin{array}{c}\text { Median Phe } \\
\text { values } \\
0-12 \\
\text { years }\end{array}$} & \multicolumn{2}{|c|}{ Phe S.D. } & \multicolumn{3}{|c|}{$\begin{array}{l}\text { Treatment adherence ( } \% \text { of Phe re- } \\
\text { sults within the recommended range) }\end{array}$} \\
\hline & & & & & $\begin{array}{c}0-6 \\
\text { years }\end{array}$ & $\begin{array}{l}7-12 \\
\text { years }\end{array}$ & $\begin{array}{c}5-6 \\
\text { years }\end{array}$ & $\begin{array}{c}7-9 \\
\text { years }\end{array}$ & $\begin{array}{l}10-12 \\
\text { years }\end{array}$ \\
\hline \multirow{3}{*}{$\begin{array}{l}\text { Wechsler } \\
\text { scale } \\
\text { scores }\end{array}$} & Full scale & $r=0.20$ & $r=-0.47$ & $r=-0.48$ & $r=0.03$ & $r=-0.42$ & $r=0.51$ & $r=0.44$ & $\begin{array}{l}r=0.65 \\
(p=0.001)\end{array}$ \\
\hline & Verbal & $r=0.25$ & $\begin{array}{l}r=-0.62 \\
(p=0.004)\end{array}$ & $\begin{array}{l}r=-0.55 \\
(p=0.024)\end{array}$ & $r=-0.07$ & $\begin{array}{l}r=-0.57 \\
(p=0.015)\end{array}$ & $\begin{array}{l}r=0.61 \\
(p=0.005)\end{array}$ & $\begin{array}{l}r=0.54 \\
(p=0.031)\end{array}$ & $\begin{array}{l}r=0.72 \\
(p=0.0001)\end{array}$ \\
\hline & Performance & $r=0.15$ & $r=-0.30$ & $r=-0.35$ & $r=0.07$ & $r=-0.28$ & $r=0.34$ & $r=0.31$ & $r=0.50$ \\
\hline
\end{tabular}

patients $(7$ th-12th years), with verbal scores were weaker $(\mathrm{r}=-0.55$ and -0.57 , respectively).

The full Wechsler scores and the performance scores did not correlate significantly with any of the assessed parameters.

We next analyzed the correlations of IQ with treatment adherence during the selected periods of life. The results attained statistical significance and revealed moderate-to-strong correlations of verbal scores and treatment adherence for all three analyzed periods: preschool, early primary school and the late primary school $(\mathrm{r}=0.61$, 0.54 and 0.72 , respectively). Interestingly, correlation for the period corresponding to the 7 th-9th years of life was the weakest and only minimally exceeded the threshold of statistical significance. The full Wechsler scores were significantly correlated with the treatment adherence only during the late primary school $(\mathrm{r}=0.65)$, and the correlations of the performance scores did not attain statistical significance.

The raw data of the blood Phe concentrations and the results of the psychological testing are presented in Table 2. The results of statistical analyses can be found in Table 3. The relation between verbal scores and treatment adherence in the late primary school period is presented in Fig. 1.

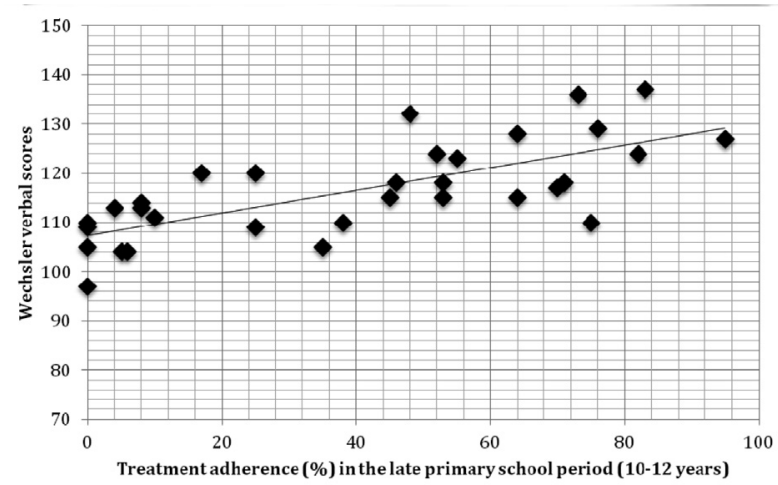

Figure 1. Relation between the Wechsler verbal scores and treatment adherence during the late primary school period.

\section{DISCUSSION}

We have demonstrated that in the early and continuously treated teenagers with PKU, the mean lifetime blood Phe levels are more closely related to cognitive outcome than the lifetime variability of blood Phe and the lifetime median Phe levels. We have also shown that the mean of the yearly mean Phe levels is the best biochemical predictor of final IQ. This finding is somewhat at odds with previously published observations (Viau et al., 2001; Anastasoaie et al., 2008) that did not find any significant correlations between a high mean Phe and a poor cognitive outcome. However, the observed discrepancies might be related to the population characteristics since the studies referenced above were largely focused on younger patients. In older children, the mean Phe concentration increases and its effect becomes more pronounced, as observed in our data.

Interestingly, the average IQ score in our patients exceeded the expected mean value in the general population (100 points). This raises questions on potential testing bias and potential overestimation of IQ in these patients. The learning effect (every participant of this study has been already assessed with the use of the same version of the WISC-R test in the early primary school period), or the so-called Flynn effect, referring to "ageing" of the test resulting in a rise of the average test scores in a population over time (Flynn et al., 1987), could partially explain this finding. However, it should be also noted, that the parents of children with well-controlled PKU make every effort to stimulate the cognitive development of their children, and some forms of cognitive training could result in an increase of the test scores obtained by this group of patients.

Our data confirmed that treatment adherence, which can be measured by means of the percentage of Phe levels within the recommended range, decreases from infancy through adolescence. Although the observed correlation of this parameter with IQ was the highest during late primary school, it was also significant during preschool. These findings suggest that both periods are critical for the intellectual outcome of patients with PKU. Therefore, the development of more efficient follow-up strategies specifically targeting preschool children and young teenagers should be considered to increase the safety of these patients and help them reach their full intellectual potential.

The second parameter, which could indirectly represent the treatment adherence (i.e., the frequency of Phe testing), did not correlate significantly with the IQ scores in our population. However, since the frequency of Phe testing depends on the stability of blood Phe and because some patients manage to maintain good metabolic control based on the results of only few tests administered yearly, this parameter appears to be less informative for assessment of treatment adherence.

Although a worldwide consensus regarding optimal blood Phe levels in patients with PKU does not exist, current treatment policies in the majority of the developed countries (van Spronsen et al., 2017) focus on the necessity of maintaining Phe below $6 \mathrm{mg} / \mathrm{dL}$ in patients younger than 12 years of age. Our data support this recommendation. Careful data analysis leads to the conclu- 
sion that cognitive outcome is optimal in patients with a mean (the mean of the yearly means) Phe remaining below $6 \mathrm{mg} / \mathrm{dL}$ during the first 12 years of life. However, since occasional spikes in blood Phe occur in nearly every child, a question arises: what is the maximal percentage of Phe levels exceeding the recommended range that is safe for patients? Although assessment of a larger number of patients with PKU appears to be necessary to ultimately answer this question, an analysis of Fig. 1 suggests that a percentage below $50-60 \%$ decreases the likelihood of optimal intellectual development.

\section{CONCLUSIONS}

In summary, based on our observations, the mean of the yearly means of blood Phe concentration within the first 12 years of age appears to be a better predictor of cognitive outcome in children with PKU than other parameters related to hyperphenylalaninemia. Since the preschool (5th-6th year) and the late primary school periods seem to be critical for intellectual development, special care should be given to improving the metabolic stability of patients at this age. A percentage of acceptable Phe levels below $50-60 \%$ should be regarded as a "red flag" due to the risk of intellectual deterioration in patients.

\section{Acknowledgements}

We would like to thank Magdalena Nitecka, MSc for critical reading of the manuscript and valuable comments.

\section{Funding}

This work was supported by the Nutricia Research Foundation (grant number 02/2011).

\section{REFERENCES}

Anastasoaie V, Kurzius L, Forbes P, Waisbren S (2008) Stability of blood phenylalanine levels and IQ in children with phenylketonuria. Mol Genet Metab 95: 17-20. doi: 10.1016/j.ymgme.2008.06.014.

Bik-Multanowski M, Didycz B, Mozrzymas R, Nowacka M, Kaluzny L, Cichy W, Schneiberg B, Amilkiewicz J, Bilar A, Gizewska M, Lange A, Starostecka E, Chrobot A, Wojcicka-Bartlomiejczyk BI, Milanowski A (2008) Quality of life in noncompliant adults with phenylketonuria after resumption of the diet. J Inherit Metab Dis 31: S415-S418. doi: 10.1007/s10545-008-0978-7

Blau N, van Spronsen FJ, Levy HL (2010) Phenylketonuria. Lancet 376: 1417-1427. doi: 10.1016/S0140-6736(10)60961-0

Burgard P, Bremer HJ, Buhrdel P, Clemens PC, Monch E, Przyrembel H, Trefz FK, Ullich K (1997) Rationale for the German recommendations for phenylalanine level control in phenylketonuria. Eur J Pediatr 158: 46-54

Flynn JR (1987) Massive IQ gains in 14 nations: What IQ tests really measure. Psycbological Bulletin 101: 171-191

van Spronsen FJ, van Wegberg AM, Ahring K, Bélanger-Quintana A, Blau N, Bosch AM, Burlina A, Campistol J, Feillet F, Giżewska M, Huijbregts SC, Kearney S, Leuzzi V, Maillot F, Muntau AC, Trefz FK, van Rijn M, Walter JH, MacDonald A (2017) Key European guidelines for the diagnosis and management of patients with phenylketonuria. Lancet Diabetes Endocrinol pii: S2213-8587(16)30320-5. doi: 10.1016/S2213-8587(16)30320-5.

Viau KS, Wengreen HJ, Ernst SL, Cantor NL, Furtado LV, Longo N (2001) Correlation of age-specific phenylalanine levels with intellectual outcome in patients with phenylketonuria. J Inherit Metab Dis 34: 963-971. doi: $10.1007 / \mathrm{s} 10545-011-9329-1$

Waisbren S, Noel K, Fahrbach K, Cella C, Frame D, Dorenbaum A, Levy H (2007) Phenylalanine blood levels and clinical outcomes in phenylketonuria: a systematic literature review and meta-analysis. Mol Genet Metab 92: 63-70

Walter JH, White FJ, MacDonald A (2002) How practical are recommendations for dietary control in phenylketonuria? Lancet 360: $55-57$ 